\title{
Chronic eosinophilic pneumonia
}

\author{
BERNARD FOX AND WILLIAM A SEED \\ From the Departments of Histopathology and Medicine, Charing Cross Hospital Medical School, London
}

ABSTRACT We describe three cases of eosinophilic pneumonia of unknown aetiology investigate产 clinically and by lung biopsy. The illnesses lasted between six and 20 weeks and consisted of cough dyspnoea, malaise, and in two cases prolonged pyrexia. All had blood eosinophilia and chesto radiographs showing widespread bilateral shadowing; in two cases this had a characteristic perer ipheral distribution. One patient recovered spontaneously and the other two responded to steroids with disappearance of pyrexia within 12 hours and radiological clearing within 14 days. Lung function tests during the acute illness showed volume restriction or gas transfer defects or both in two cases. After remission all three showed abnormalities of small airways function. Lung biopsies performed during the acute illness were examined histologically and by transmission electrores microscopy, and in two cases by immunofluorescence. There was both intra-alveolar and inter $\vec{\oplus}$ stitial eosinophilic pneumonia with bronchiolitis obliterans, microgranulomata, and a vasculitisoo Electron microscopy showed numerous eosinophils, many degranulated, and macrophages with phagocytosed eosinophilic granules and intracytoplasmic inclusions. In one case IgM, IgG, and IgA were demonstrated in the bronchial walls and interstitium. No IgE or complement was present. We believe that eosinophil granules are responsible for the tissue damage and fever, and sugges, mechanisms for this and for the response to steroid therapy.

Chest radiographic shadowing in combination with blood eosinophilia occurs in a number of clinical contexts, and these have been divided by Crofton et al, ${ }^{1}$ on purely clinical grounds, into five categories: (1) simple pulmonary eosinophilia (Löffler's syndrome); (2) prolonged pulmonary eosinophilia without asthma; (3) pulmonary eosinophilia with asthma; (4) tropical pulmonary eosinophilia; (5) polyarteritis nodosa.

However, cases occur which run a chronic course and are difficult to fit into this classification, since they may or may not have asthma. Carrington and his colleagues ${ }^{2}$ have used the term chronic eosinophilic pneumonia to describe these, and have demonstrated that lung biopsies from such cases show a uniform histological appearance. Lung function, ultrastructure, and immunofluorescent studies of biopsy material have rarely been reported. We describe three cases of chronic eosinophilic pneumonia in which these aspects were investigated.

\section{Case reports}

CASE 1

A 72-year-old priest presented with a three-

Address for reprint requests: Dr WA Seed, Department of Medicine, Charing Cross Hospital Medical School, London W6. month history of worsening effort dyspnoea, drô? cough, malaise, fever with night sweats, and cccasional rigors. His appetite was poor and he had lost $10 \mathrm{~kg}$ in weight. He had a history of mild asthma for 12 years (treated with salbuta mol and intermittent beclomethasone by inhala@ tion), and myocardial ischaemia (treated wits digoxin and frusemide).

On admission he was febrile $\left(38.1{ }^{\circ} \mathrm{C}\right)$ and un well. The only abnormal signs were in his chest where there were widespread sparse wheezes, and crackles confined to the left upper zone.

Chest radiography (fig 1) showed shadowing in the left uprer and mid-zones, most marke peripherally, and patchy changes in the rightr upper zone. Tests produced the following resultsin $\mathrm{Hb}-13.3 \mathrm{~g} / \mathrm{dl}$; WBC $-12.3 \times 10^{9} / 1$, with $52 \%$ neutrophils, $11 \%$ lymphocytes, $7 \%$ monocytes and $30 \%$ eosinophils (absolute eosinophil counf $3.69 \times 10^{9} / 1$ ); ESR-over $100 \mathrm{~mm} / \mathrm{hr}$; sputum-C light growth of Candida albicans, but no sige nificant pathogens isolated from many samples; serum immunoglobulins-IgG $21 \mathrm{~g} / 1$, IgA $3 \cdot 1 \mathrm{~g} / 1$, IgM $1.7 \mathrm{~g} / 1$, IgE 240 (later 94) IU $/ \mathrm{mI \mathbb {S }}$ The results of lung function tests are shown if table 1. Arterial blood gases with the patienf breathing air were $\mathrm{pO}_{2} 55 \mathrm{mmHg}, \mathrm{pCO}_{2} 33 \cdot 5$ $\mathrm{mmHg}, \mathrm{pH} \mathrm{7 \cdot 44}$. Skin test reactions to commois 


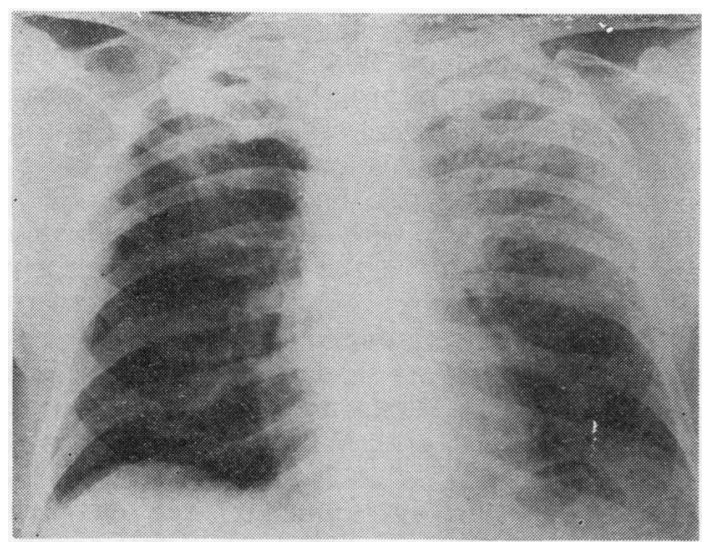

Fig 1 Chest radiograph of case 1, showing shadowing in both upper zones

Table 1 Lung function tests during acute illness. Cases 1 and 3 were studied before biopsy, case 2 one week after biopsy. Figures in brackets are the value expressed as a percentage of the predicted normal value. Values more than $2 S D$ from the predicted normal value are starred. Predicted normal values are derived from Cotes. 4

\begin{tabular}{|c|c|c|c|}
\hline Lung function tests & Case 1 & Case 2 & Case 3 \\
\hline \multicolumn{4}{|l|}{ Airways measurements } \\
\hline FEV $_{1}$ (IBTPS) & $2 \cdot 10 \quad(91)$ & $* 1.35 \quad(57)$ & $3 \cdot 40(133)$ \\
\hline FVC (IBTPS) & $2.90(86)$ & $* 1.45 \quad(50)$ & $4 \cdot 15(127)$ \\
\hline FEV $_{1} /$ FVC (\%) & 73 (113) & $92(115)$ & $81(100)$ \\
\hline $\begin{array}{l}\text { PEFR (IBTPS S S-1) } \\
\text { Volumes (He dilution) IBTPS }\end{array}$ & $5 \cdot 3 \quad(67)$ & *2.9 (47) & $8 \cdot 5$ (129) \\
\hline FRC & $* 2 \cdot 20 \quad(61)$ & $2 \cdot 0 \quad(75)$ & $3 \cdot 25(113)$ \\
\hline TLC & $4 \cdot 55 \quad(78)$ & *2.85 (64) & $5 \cdot 75(115)$ \\
\hline VC & 3.06 (91) & $* 1.47 \quad(51)$ & 4.44 (136) \\
\hline $\mathbf{R V}(\mathrm{s}$ & $1.49 \quad(66)$ & $1.40(92)$ & 1.32 (77) \\
\hline RV (single breath) & $* 1.35 \quad(60)$ & 1.50 (99) & $1 \cdot 30(76)$ \\
\hline Gas transfer (single $b$ & & & \\
\hline Dco $\left(\mathrm{mmol} \mathrm{CO} \mathrm{min}^{-1} \mathrm{kPa}^{-1}\right)$ & $4.98 \quad(69)$ & *3.14 (41) & $9 \cdot 13(112)$ \\
\hline $\mathrm{Kco}\left(\left.\mathrm{mmol} \mathrm{CO} \min ^{-1} \mathrm{kPa}^{-1}\right|^{-1}\right)$ & $1 \cdot 34(107)$ & $*^{* 1.25} \quad(72)$ & $1 \cdot 72(98)$ \\
\hline
\end{tabular}

allergens, including Aspergillus sp, were negative. Results of other investigations, listed below, were negative.

During the next four weeks the patient remained unwell and pyrexial, with a mild normochromic, normocytic anaemia ( $\mathrm{Hb} \quad 10.7 \mathrm{~g} / \mathrm{dl}$ ) and variable eosinophilia $\left(0.1\right.$ to $4.2 \times 10^{9} /$ litre $)$. Serial chest radiographs showed some extension of the shadowing in the left lung, but the upper zone changes in both lungs remained static. Bronchoscopy revealed small, pale nodules in the left upper lobe and left apical lower lobe bronchi, but was otherwise normal. Biopsies of the nodules revealed non-specific chronic inflammation with plasma cell, neutrophil, and eosinophil infiltration.

Four weeks after presentation, open biopsy of the left upper lobe was performed. At operation the lobe was consolidated, with fine adhesions to the chest wall and pericardium and patchy consolidation in the lower lobe. There was no pleural fluid. Postoperatively, fever and intermittent eosinophilia continued, and oral prednisolone, $30 \mathrm{mg} /$ day, was started. The temperature resolved within 12 hours (fig 2) and the chest radiograph after two weeks was clear apart from a small area of scarring at the left apex which antedated the present illness. Prednisolone was gradually withdrawn over six months and the patient remained clinically and radiologically well for several months. Lung function studies during this remission are listed in table 2. Five months after withdrawal of steroids he relapsed, with fresh shadowing in the posterior part of the right lower lobe (an area previously spared) and eosinophilia of $3.4 \times 10^{9} / 1$. The principal symptom on this occasion was dyspnoea, with clinical and functional evidence of gross airways obstruction $\left(\mathrm{FEV}_{1} \mathbf{0 . 8 5}\right.$ 1, FVC 1.6 1). He made

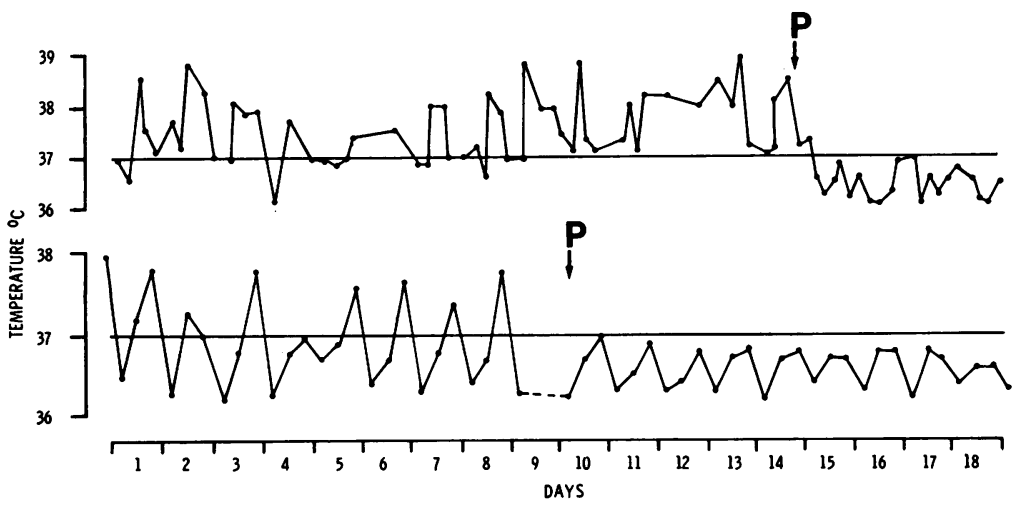

Fig 2 Temperature charts from cases 1 (lower) and 2 (upper) showing the effect of starting oral steroid therapy (P). - - - indicates an outpatient period with no measurements. 
Table 2 Lung function tests during remission and off treatment. Notation and units (except where given) as table 1. Predicted normal values for $V_{\max }$, $50 \% V^{5}$; closing volume, ${ }^{6}$ phase 3 slope, ${ }^{7}$ mixing index-our laboratory unpublished.

\begin{tabular}{|c|c|c|c|}
\hline Lung function tests & Case 1 & Case 2 & Case 3 \\
\hline \multicolumn{4}{|l|}{ Airways measurements } \\
\hline$F^{r}=V_{1}$ & $2 \cdot 10 \quad(91)$ & $2 \cdot 10 \quad(90)$ & $3 \cdot 15(123)$ \\
\hline FVC & $2.95 \quad(89)$ & 2.65 (93) & $4 \cdot 00(122)$ \\
\hline FEV $/$ FVC & 71 (111) & $80(100)$ & $79(100)$ \\
\hline PEFR & $7.01 \quad(90)$ & $5.43 \quad(89)$ & $7 \cdot 36(111)$ \\
\hline Vmax, $50 \%$ VC (1BTPSs $\left.{ }^{-1}\right)$ & *1.08 (33) & $* 2.68 \quad(70)$ & $* 2.75 \quad(71)$ \\
\hline $\begin{array}{l}\text { Closing volume (\%VC) } \\
\text { Phase } 3 \text { slope }\left(\% \mathrm{~N}_{2} \text { IBTPS }^{-1}\right)\end{array}$ & $28 \cdot 8$ (106) & $21 \cdot 6(132)$ & $16 \cdot 1$ \\
\hline $\begin{array}{l}\text { (single breath } \mathrm{N}_{2} \text { test) } \\
\text { Volumes }\end{array}$ & $* 2 \cdot 1 \quad(140)$ & $1 \cdot 2(80)$ & $1 \cdot 4(100)$ \\
\hline FRC & $4 \cdot 25(131)$ & $3.0(128)$ & $3 \cdot 25(113)$ \\
\hline TLC & $6 \cdot 70$ (117) & $4 \cdot 8(110)$ & $6 \cdot 15(123)$ \\
\hline & $3 \cdot 14$ (95) & $2 \cdot 70(95)$ & $4 \cdot 54$ (139) \\
\hline RV (steady state) & *3.56 (159) & $2 \cdot 12(143)$ & $1.58 \quad(92)$ \\
\hline RV (single breath) & $1.75 \quad(78)$ & $0.95(64)$ & $1.15 \quad(67)$ \\
\hline $\begin{array}{l}\text { Mixing index }(\mathrm{RV} / \mathrm{sB} \\
\text { RVss } \times 100)\end{array}$ & $* 49$ & *45 & *73 \\
\hline \multicolumn{4}{|l|}{ Gas transfer } \\
\hline Dco & $5 \cdot 52 \quad(79)$ & $5 \cdot 54$ (73) & $10 \cdot 85(133)$ \\
\hline Kсо & $1.29(104)$ & $1.66(95)$ & 1.94 (111) \\
\hline
\end{tabular}

a rapid response to oral prednisolone $60 \mathrm{mg} /$ day, plus an initial continuous infusion of salbutamol, and remains well on a tapering dose of prednisolone. The effect of steroids on the blood eosinophilia is shown in fig 3.

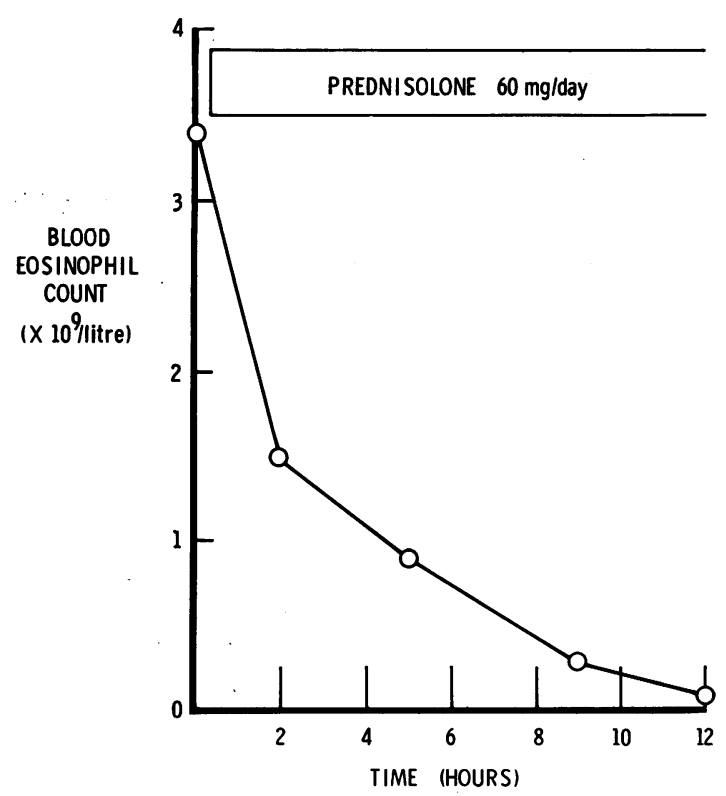

Fig 3 Case 1: effect of oral steroid therapy on blood eosinophil count.
CASE 2

A 47-year-old female filing clerk presented wi a six-week history of progressive dyspnoea, wea ness, and $7 \mathrm{~kg}$ weight loss. Her previous histo was healthy. On admission she was thin and in with pyrexia to $39^{\circ} \mathrm{C}$. Abnormal signs were contr fined to the chest, with dullness to percussion and sparse crackles at the right base anteriorly

Chest radiography (fig 4) showed extensivi patchy shadowing throughout the right lung, and more localised linear shadowing in the left mix and lower zones. Tests produced the following results: $\mathrm{Hb}-11.1 \mathrm{~g} / \mathrm{dl}$; WBC $-14.3 \times 10^{9} / 1$, witho $91 \%$ neutrophils, $4 \%$ lymphocytes, and $5 \%$ monocytes; ESR-92 $\mathrm{mm} / \mathrm{hr}$; sputum-ligh growth of penicillin-sensitive coagulase-positive Staphylococcus aureus; serum immunoglobulins -IgG $11.0 \mathrm{~g} / 1, \operatorname{IgA} 3.8 \mathrm{~g} / 1$, IgM $1.5 \mathrm{~g} / 1$, IgE $<30 \mathrm{IU} / \mathrm{ml}$. Arterial blood gases with the patient breathing $40 \%$ oxygen were $\mathrm{pO}_{2} 12 \frac{2}{8}$ $\mathrm{mmHg}, \mathrm{pCO}_{2} 38 \mathrm{mmHg}$, pH 7.38.

The patient was treated with ampicillin and flucloxacillin, $500 \mathrm{mg}$ six hourly, for eight dayes without clinical or radiological improvement Repeated sputum cultures were sterile apa角 from occasional isolations of Candida albicand Blood counts showed a progressive fall in haemo globin to $7.9 \mathrm{~g} / \mathrm{dl}$, and leucocytosis $(12 \cdot 0-14.8$ $\times 10^{9} / 1$ ) with $84-86 \%$ of neutrophils and $4-5 \%$ eosinophils (absolute eosinophil counts 0.56 $\left.0.59 \times 10^{9} / 1\right)$.

She remained severely ill and after two weeks was started on antituberculous chemotherapy However, she continued to deteriorate, and further chest films showed extension of shadowing throughout the left lung and in the right upper zone. ESR and white blood count remained

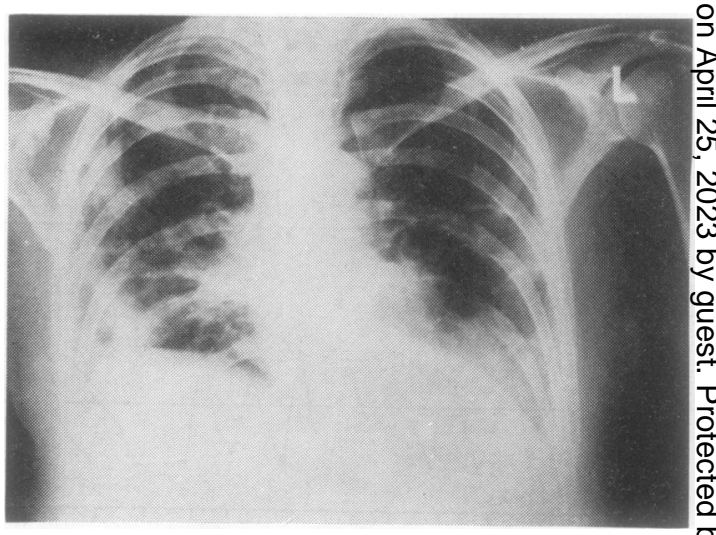

Fig 4 Chest radiograph of case 2, showing bilaterăt peripheral shadowing. 
high and a modest eosinophilia (up to $1 \cdot 10 \times$ $\left.10^{9} / 1\right)$ persisted. After four weeks in hospital she was transfused with three units of blood and open biopsy of the left upper lobe was performed. At operation, the whole left lung appeared inflamed, with a few pleural adhesions but no effusion. Post operatively she remained pyrexial until prednisolone $30 \mathrm{mg}$ a day was started, when her temperature rapidly settled (fig 2) and she improved clinically. The eosinophil count was normal five days later, and chest radiograph after two weeks showed only a small area of shadowing in the right mid-zone and leftsided pleural changes secondary to the thoracotomy. Tomography of the lesion in the right lung showed a $1 \mathrm{~cm}$ area of shadowing consistent with localised fibrosis. Prednisolone was gradually withdrawn and then stopped after six months, and the patient remains well. Lung function tests performed six days after the start of steroid treatment, and one week after withdrawal of steroids, are tabulated in tables 1 and 2.

\section{CASE 3}

A 46-year-old beautician presented with a twomonth history of dry cough, followed by anorexia, weight loss $(3 \mathrm{~kg})$, and night sweats. For one week before admission she had noticed mild effort dyspnoea. Her previous health had been good. On admission she appeared well and was afebrile; abnormal physical signs were confined to the chest, where there was evidence of consolidation in the right upper zone.

Chest radiography (fig 5) showed extensive peripheral shadowing in the right upper and mid zones and similar but more localised changes in

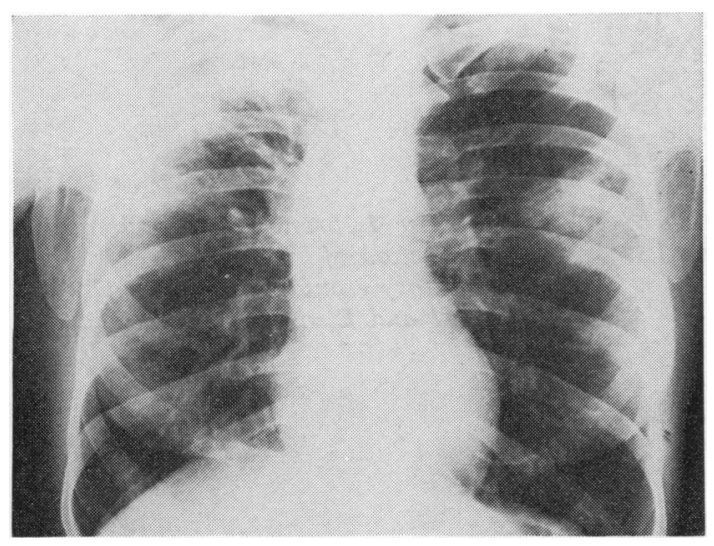

Fig 5 Chest radiograph of case 3, showing peripheral shadowing in upper and mid zones. the left mid-zone. Tests produced the following results: $\mathrm{Hb}-11.4 \mathrm{~g} / \mathrm{dl}$; $\mathrm{WBC}-11.6$ $\times 10^{9} / 1$, with $40 \%$ neutrophils, $10 \%$ lymphocytes, $3 \%$ monocytes, $47 \%$ eosinophils (absolute eosinophil count $5 \cdot 36 \times 10^{9} / 1$ ); ESR $-79 \mathrm{~mm} / \mathrm{hr}$. The sputum was extremely sparse, mucoid, and contained no pathogens. Lung function tests prociuced normal results (table 1). Arterial blood gases with the patient breathing air were $\mathrm{pO}_{2} 89 \mathrm{mmHg}, \mathrm{pCO}_{2} 32 \mathrm{mmHg}, \mathrm{pH} 7 \cdot 41$. Serum immunoglobulins were IgG $20.8 \mathrm{~g} / \mathrm{l}$, IgA 1.5 $\mathrm{g} / 1, \mathrm{IgM} 1.8 \mathrm{~g} / \mathrm{l}, \mathrm{IgE} 91 \mathrm{IU} / \mathrm{ml}$. Skin testing was positive to a number of common allergens, though not to Aspergillus. She remained afebrile, with only minor symptoms, but blood eosinophilia persisted with absolute counts between 3.42 and $7.0 \times 10^{9} / 1$. Chest radiography showed extension of the shadowing in the left lung to the upper zone, and slight clearing on the right. Two weeks after admission transbronchial biopsy of the right upper lobe was performed via a fibreoptic bronchoscope, and shortly after this she was allowed home. Three weeks later, her chest film showed complete clearing, and has remained normal during six months follow-up though a mild blood eosinophilia persists $(0.6$ $-0.9 \times 10^{9} /$ litre).

\section{Other investigations}

The following investigations were carried out on all three patients and were normal or negative: serum electrolytes, urea, creatinine, calcium, phosphate; liver function tests; serological tests for syphilis; Widal test; immunofluorescent tests for antibodies to thyroid colloid, thyroid epithelial cell cytoplasm, gastric parietal cell cytoplasm, nuclei (ANF), mitochondria, and smooth muscle; serial complement fixation tests against the following respiratory pathogens-adenovirus, cytomegalovirus, influenza $\mathrm{A}, \mathrm{B}$, and $\mathrm{C}$, parainfluenza 1 and 3 , psittacosis, respiratory syncytial virus, Mycoplasm, Coxiella burneti; serum precipitins to Aspergillus; filarial fluorescent antibody test; microscopy and culture of faeces; culture of throat swabs, MSU, and blood; urine and sputum culture for mycobacteria.

Apart from the drugs mentioned in case 1, none of the patients had been on any treatment in the months preceding their illness. Case 1 had travelled to Australia in the early stage of his illness, without leaving the aircraft en route; neither of the others had been abroad within the previous 12 months.

EXAMINATION OF LUNG TISSUE

The open biopsies (cases 1 and 2) were divided 
into four. One piece was used for transmission electron microscopy and fixed in Karnovsky fixative for four hours at $4^{\circ} \mathrm{C}$. It was then washed overnight in cacodylate-sucrose buffer at $4{ }^{\circ} \mathrm{C}$ and then post-fixed in $1 \%$ aqueous osmium tetroxide for one hour at $4^{\circ} \mathrm{C}$. After rinsing in distilled water it was dehydrated to absolute ethanol, then placed in epoxypropane and fresh warm Araldite, and finally embedded in fresh Araldite. Sections were stained with uranyl acetate and lead nitrate, and examined in a Phillips 201 electron microscope.

Another sample was cultured for bacteria, fungi, and viruses and nothing was grown. A further piece was frozen for immunofluorescent studies, and the remainder of the tissue was fixed in $4 \%$ neutral formaldehyde for histology $\stackrel{\vec{F}}{\stackrel{\vec{P}}{+}}$ In case 3 (fibreoptic biopsy) observations were limited to histology and electron microscopy.

\section{HISTOLOGY}

The findings in cases 1 and 2 were similar. Thछ most striking change, which was diffusely distributed throughout the lung, was consolidation; with alveoli filled by macrophages and eosino $\vec{\omega}$ phils, and widespread thickening of the alveola? walls, lobular septa, and visceral pleura by oede $\vec{x}$ matous loose vascular conective tissue infiltrated by eosinophils, plasma cells, and macrophageso (fig 6). There were many "eosinophilier abscesses" 3 composed of masses of eosinophilie granules, eosinophils, macrophages-some con음
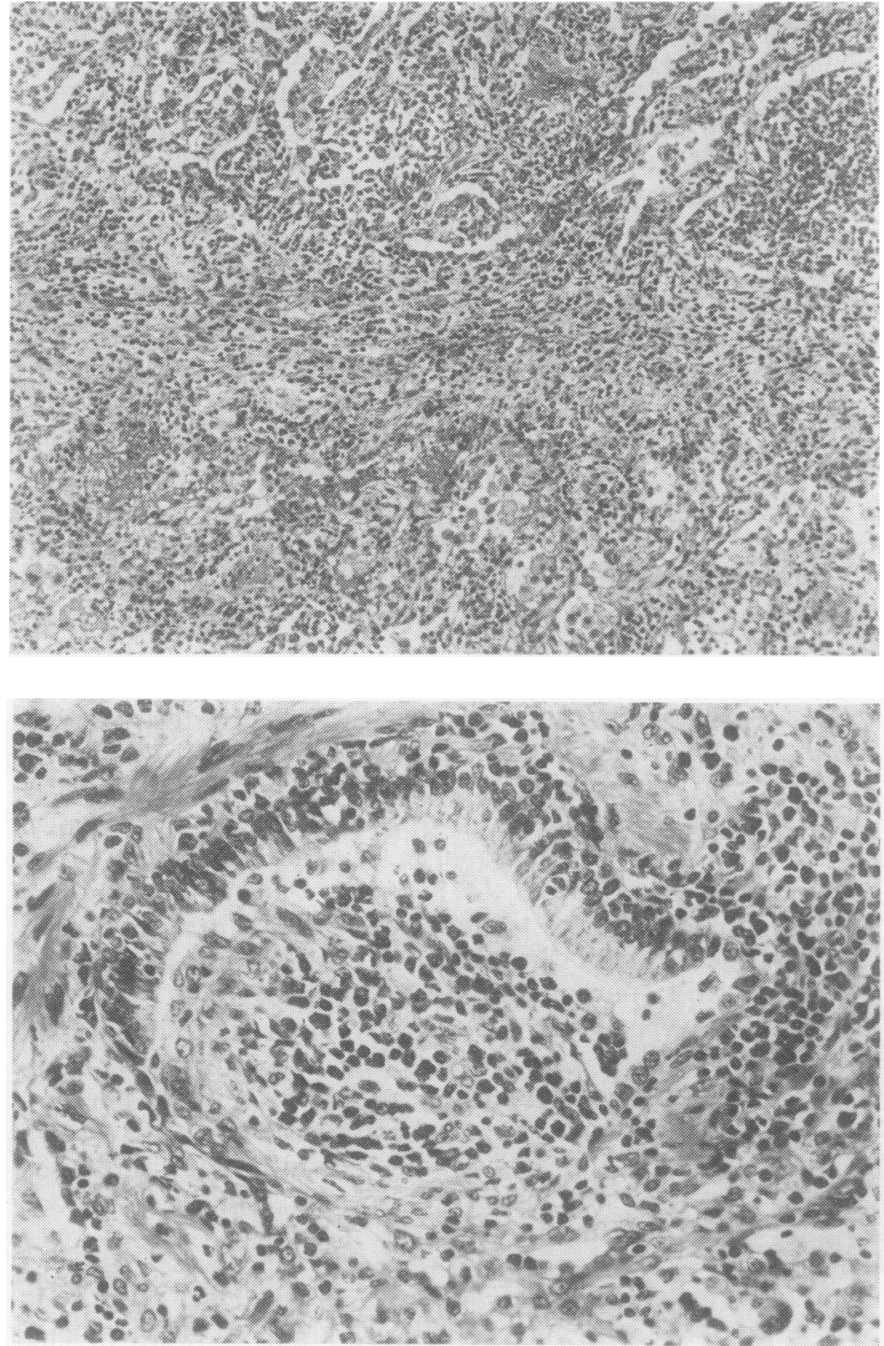

Fig 6 Case 1: lung biopsy showing intra-alveolar consolidation and cellular infiltration of alveolar and lobular septo $H$ and $E$, original magnification $\times 100$.

Fig 7 Case 1: bronchiolitis obliterans with ulceration of mucosa and inflammatory granulation tissue in lumen. $H$ and $E$, original magnification $\times 250$. 
taining eosinophilic granules-and fibrin, often with areas of necrosis, the whole lesion frequently surrounded by macrophages. There were areas of intra-alveolar organisation with vascular granulation tissue infiltrated by plasma cells, eosinophils, and a few macrophages. Many of the alveoli were lined by cuboidal cells and contained oedema fluid. There were a few microgranulomata, some related to bronchioles. There was bronchiolitis involving most of the bronchioles and in some there was ulceration of the mucosa; and the lumen was partly and in places completely occluded with granulation tissue containing eosinophils, macrophages, multinucleated giant cells, plasma cells, and fibrin (bronchiolitis obliterans) (fig 7). Some of the bronchioles were filled by mucus containing eosinophils, macrophages, plasma cells, and occasional multinucleated giant cells. In areas there was an obstructive type of pneumonia with alveoli containing many lipid-filled macrophages (fig 6).
There was a mild arteritis with eosinophils, plasma cells, and macrophages involving the adventitia and media but there was no evidence of necrosis nor were the veins involved. Small pulmonary arteries showed narrowing of the lumen by vascular connective tissue and there was also moderate hyperplasia of the media.

In case 3, there was marked peribronchial consolidation with macrophages (some containing eosinophilic granules), plasma cells and occasional clusters of eosinophils. There was also intra-alveolar organisation and obstructive lipid pneumonia similar to that seen in cases 1 and 2 . However, there was no evidence of bronchiolitis obliterans, eosinophilic abscesses, or vasculitis in the small amount of tissue available.

No organisms or fungi were seen in any of the cases.

\section{ELECTRON MICROSCOPY}

The findings were similar in all three cases. There were many eosinophils and macrophages

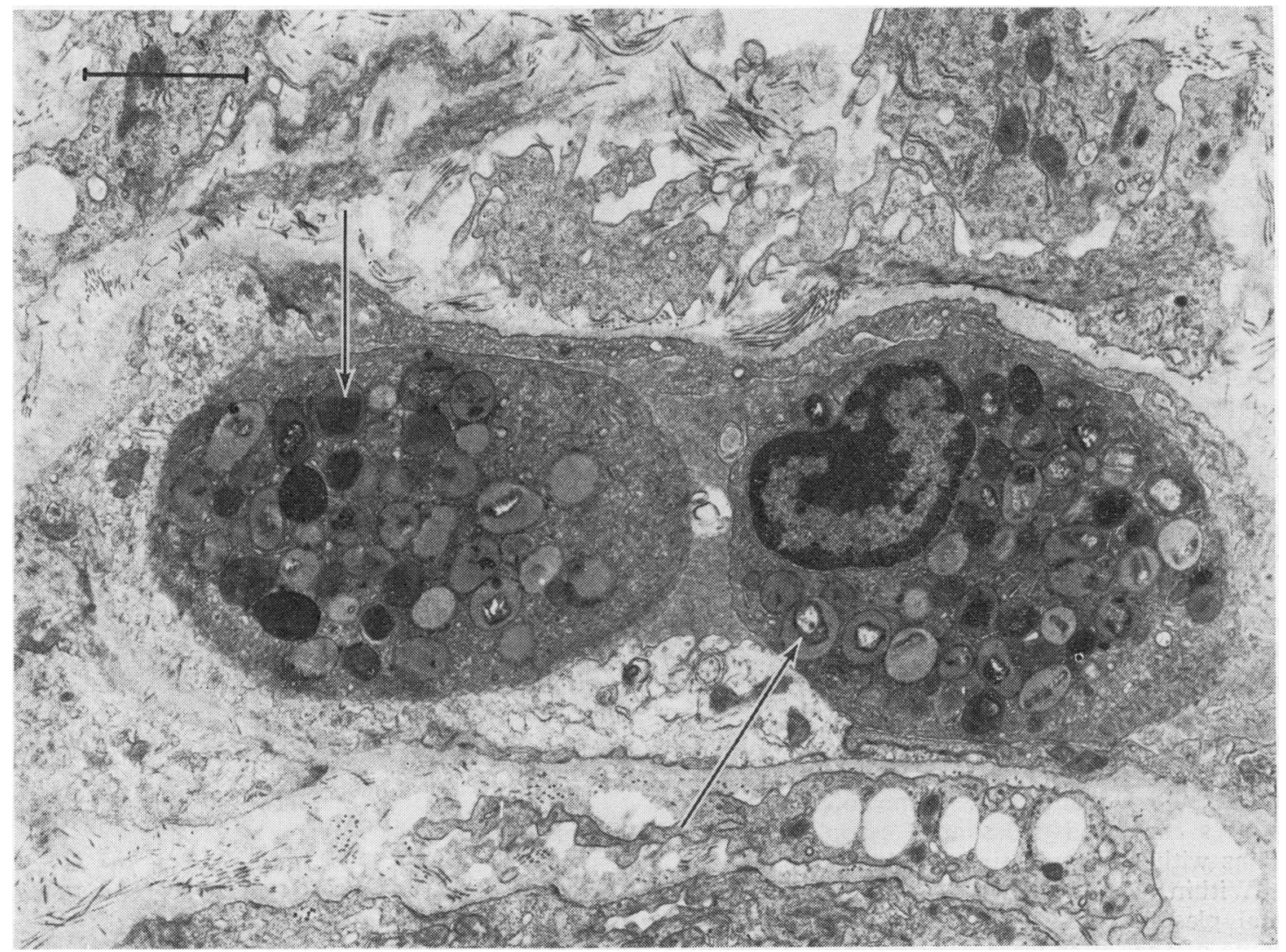

Fig 8 Case 3: eosinophil with normal (small arrow) and degranulated (large arrow) granules in alveolar capillarj'. Electron micrograph, bar mark $2 \mu \mathrm{m}$. 


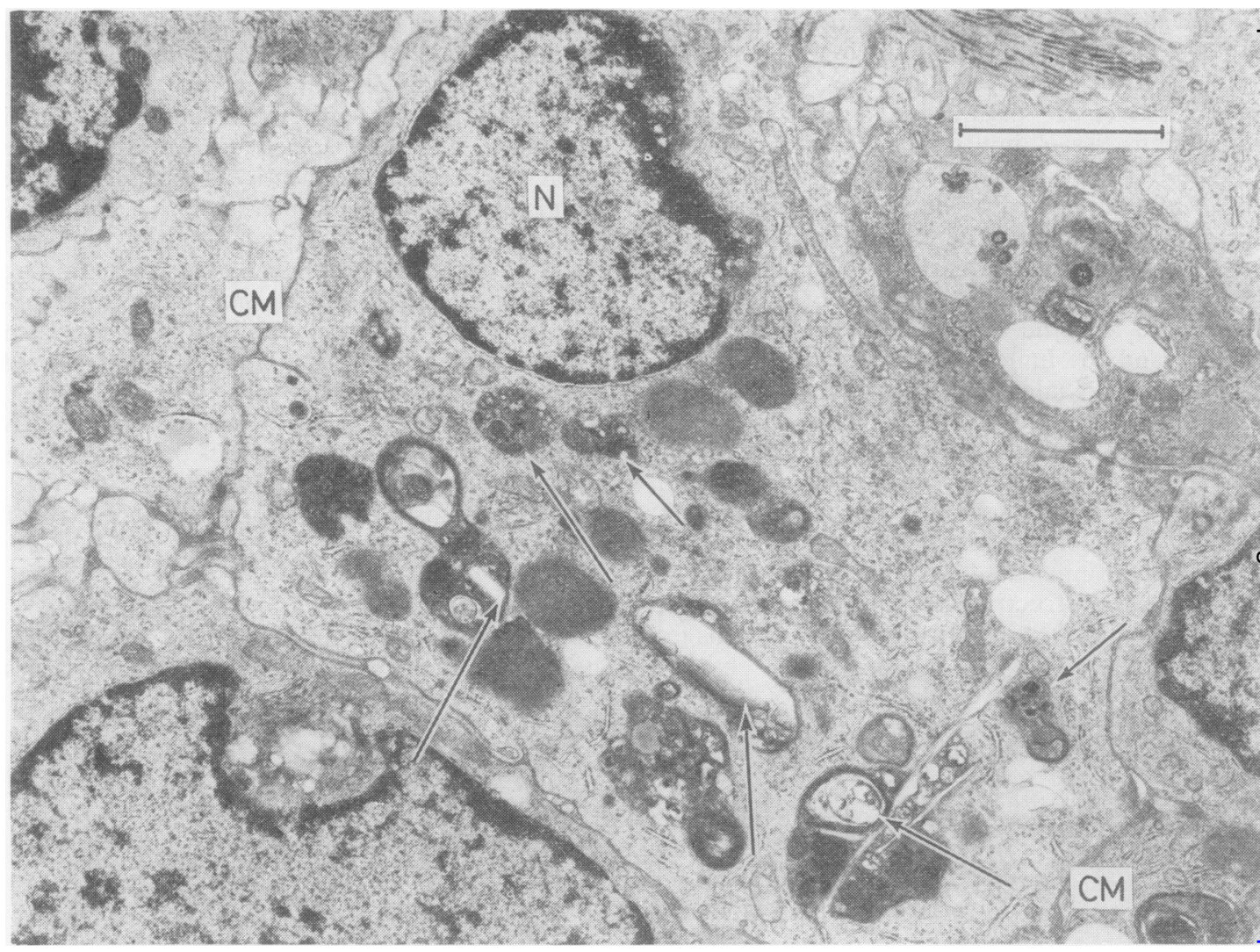

Fig 9 Case 1: macrophage (nucleus $N$ and cell membrane CM) containing cytolysosomes (small arrows) and irregular shaped translucent bodies (large arrows). Electron micrograph, bar mark 3 um.

in the alveolar spaces and interstitial tissue. There were three main types of eosinophil. One contained normal granules composed of a dense central core surrounded by a less dense matrix ${ }^{8}$; in the second the central core of the granules was translucent and the surrounding matrix was more dense. Finally there were some eosinophils which contained both types of granules, and in case 3 these were also present in an alveolar capillary (fig 8). Many of the macrophages contained eosinophilic granules and some fragments of eosinophils. There were cytolysosomes containing irregularly shaped translucent bodies (fig 9), and one macrophage in case 1 contained a rectangular shaped body surrounded by a multilayered membrane. Some of the macrophages contained odd shaped cytoplasmic inclusions with a pentalaminar wall (fig 10).

Within the interstitial tissue there were normal plasma cells, lymphocytes, and mast cells; some of the latter were degranulated. There was focal oedema of the alveolar capillary wall and in places the alveoli were lined by type 2 cells. Deposits of immune complexes were not see

IMMUNOFLUORESCENCE

In cases 1 and 2 the lungs were examined for IgA, IgG, IgM, IgE, fibrinogen, and Clq frae tion of complement using commercially prepare FITC conjugated sera. Case 1 was negative; case $2 \operatorname{IgG}, \operatorname{IgA}$, and $\operatorname{IgM}$ were present in plasmfor cells and macrophages in the interstitial tissug and in the bronchial wall, and as irregular flecks in the connective tissue of the bronchial waf. Fibrinogen was present within alveoli in both cases. In neither case was there evidence immune complexes.

\section{Discussion}

Our three cases demonstrate well the clinic and pathological spectra of chronic eosinophilß pneumonia. We have found 60 published case with biopsy or necropsy histology which matcheg 


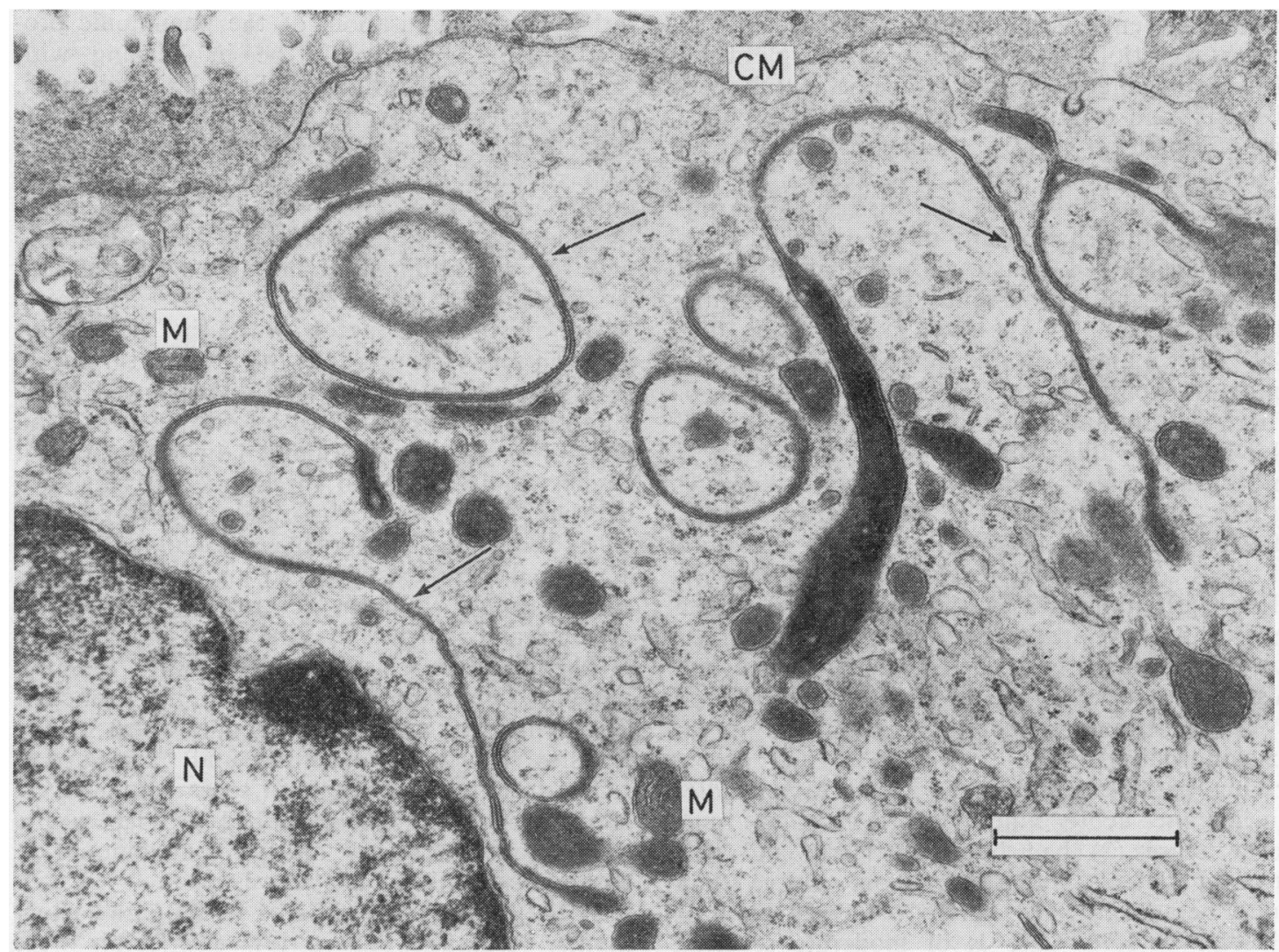

Fig 10 Case 3: macrophage (nucleus $N$, cell membrane $C M$, and mitochondria $M$ ) with pentalaminar inclusions (arrows). Electron micrograph, bar mark $1 \mu \mathrm{m}$.

that in our cases. Apart from two patients (one with bronchopulmonary aspergillosis ${ }^{3}$ and one treated with nitrofurantoin ${ }^{2}$ ) no aetiology was established. ${ }^{2} 3$ 8-23 Clinical details are only complete for about half these cases, but a remarkably coherent picture emerges which is well illustrated by our cases and summarised in table 3. The age distribution has a peak in the fifth decade, and decays symmetrically about this; but no age group is exempt. Females preponder-

Table 3 Presenting clinical features in 63 histologically confirmed cases of chronic eosinophilic pneumonia

\begin{tabular}{lcl}
\hline Feature & Incidence \% & Comment \\
\hline Radiographic shadowing & 100 & $\begin{array}{l}\text { Typical pattern in } 60 \% \\
\text { (see text) } \\
\text { May be intermittent; } \\
\text { absent throughout in } 13 \%\end{array}$ \\
Blood eosinophilia & 81 & $\begin{array}{l}\text { May reach } 40{ }^{\circ} \mathrm{C} \\
\text { Productive in } 80 \%\end{array}$ \\
Fever & 94 & Up to $24 \mathrm{~kg}$ \\
$\begin{array}{l}\text { Dough } \\
\text { Weight loss }\end{array}$ & 94 & \\
Malaise & 84 & 82
\end{tabular}

ate by two to one. Asthma was present in $53 \%$, usually with a short history (mean duration six years, and less than five years in $70 \%$ ); onset in childhood has been described only once. Eosinophilia was occasionally gross (up to 25 $\times 10^{9} /$ litre) but much more commonly was modest or intermittent (cases 1 and 2), and in a small proportion of cases it is never seen. ${ }^{2}$

Not suprisingly, severe cases (which comprise about two-thirds of the total, and present with all the features listed in table 3 ) were often treated initially as bacterial pneumonia and subjected to lung biopsy because of a downhill course, as in cases 1 and 2. However, in 60-70\% of all cases, the chest radiograph showed a peripheral pattern of shadowing (the "photographic negative of pulmonary oedema") which has recently been demonstrated to be virtually diagnostic. ${ }^{23}$ Gaensler and Carrington ${ }^{23}$ recommended that, in view of the rapid response to steroids which is typical of this disease (see below), a trial of steroid therapy is appropriate 
in such patients without biopsy. We accept this with reservation, since it will hinder exploration of a pathogenetic process which is still largely obscure; and we would recommend fibreoptic biopsy whenever possible, since we have shown it to be an effective approach (case 3 ).

The natural history of the disease is reasonably well-established. Many of the reported cases had a protracted course before diagnosis and treatment, and permanent spontaneous remission (as in case 3) was seen in less than $10 \%$. The vast majority were treated with steroids, and our experience in cases 1 and 2 is typical. There is dramatic resolution of pyrexia and blood eosinophilia followed by a rapid clinical and radiological remission. The radiograph usually clears completely within two weeks. Howiever, when steroids are withdrawn, one-third of cases sooner or later relapse (as did case 1), often with infiltrates in the same areas of the lungs. ${ }^{23}$ Such relapses, which have been recorded up to eight times in a single patient, continue to respond to steroids, and appear to be prevented by low dose maintenance therapy $(<10 \mathrm{mg}$ prednisolone daily).

Our patients all had lung function studies during the acute illness (table 1). The most severe case (2) had both restrictive and gastransfer defects, the latter more severe than could be accounted for solely by the reduction of alveolar volume. Case 1, of moderate severity, had a borderline restrictive defect only during the first attack; the recurrence 15 months later was dominated by gross airways obstruction. Case 3, which was very mild, retained normal lung function.

There are few detailed reports of lung function during the acute untreated illness. ${ }^{2} 121519$ These are in keeping with our findings, and we can summarise the acute situation thus: mild cases may have normal lung function; with increasing severity volume restriction and a true defect of gas transfer appear. In patients with a previous history of asthma, airways obstruction may occasionally be the dominant abnormality. Hypoxaemia caused by disturbed ventilationperfusion relationships may be severe $\left(\mathrm{pO}_{2}<50\right.$ $\mathrm{mmHg}$ ). Three deaths have been reported. 31623

Our cases also illustrate the reversibility of these lung function abnormalities with steroid treatment; in particular, gas transfer defects are eliminated $^{2}$ and fixed volume restriction is unusual except in those patients with a severe, protracted course before treatment or with repeated recurrences after steroid withdrawal. The response to steroids suggests that resolution, rather than organisation, of the pneumonic pro? cess occurs. This would be in keeping witle the dominance of cellular and exudative changes $\overline{\bar{m}}$ rather than necrosis, in biopsy specimens, and is supported by the observation of Perrault et al, 10 who repeated a needle biopsy of their patients during remission. The only abnormality $\operatorname{seen} \vec{\sigma}$ in what had previously been a florid and typicat picture, was minimal peribronchial fibrosis and a single healed granuloma.

However, we disagree with the impression given in many reports that the process is entirel reversible. Both our open biopsies showed brono chiolitis obliterans. In view of this, we included tests of small airways function in the remission studies (table 2). In all three cases at least tw $\bar{\Theta}$ of these tests were abnormal. We, therefore believe that an irreversible residuum of smat airways disease exists in our patients, probabl commensurate with the severity of the originat episode, and that this may be a common feature of the disease. Tests of small airways function have not been reported previously, but bronchioe litis obliterans was a feature of a third of the biopsies reported by Gaensler and Carrington. $\frac{2 \frac{3}{3}}{0}$

The histological changes in cases 1 and 2 wer characteristic of those described by Liebow an Carrington. ${ }^{3}$ In case 3 only a small amount of tissue was available but it was possible to con firm the clinical diagnosis of eosinophilic pneus monia. Although only a few eosinophils were found in the histological sections many more were seen by electronmicroscopy. The explana tion for this disparity is that on electronmicros copy it is easy to identify both normat and degranulated eosinophils whereas onl eosinophils with normal granules will be readilg identified in histological sections. ${ }^{24}$

We have no direct evidence as to the cause of eosinophilia in chronic eosinophilic pneumos nia. Eosinophilia can accompany all four types of immune reaction. ${ }^{24}$ In type 1 reactions mast cell degranulation appears to be the trigger. Hover ever it is unlikely that this could play a signifn cant role in a disease with such a prolonged and stable pulmonary reaction, and all ous patients had normal serum IgE levels. Activa tion of complement appears to be the stimulus for eosinophilia in types 2 and 3 reactions bue we found no evidence of complement activation in our cases. In type 4 (cell-mediated) reactions blood eosinophilia may be caused by the releas from lymphocytes of eosinophilic stimulatin and chemotactic factors. ${ }^{24}$ We interpret the presence of microgranulomata as evidence of a cell-mediated immune reaction and we favoug 
this as the cause in our cases.

The eosinophil appears to play a crucial role in the pathogenesis of this disease; it is the predominant cell in the tissue reaction, blood eosinophilia is usually present in the active stage, and when remission is produced by steroids eosinophilia rapidly disappears. It has been suggested that the damage to the heart in Löffler's cardiomyopathy is caused by the eosinophilic granules; ${ }^{25}$ cardiomyopathy is not a feature of chronic eosinophilic pneumonia but this may be because the eosinophilia is milder and much less prolonged. However it is possible that the release of eosinophilic granules locally and in high concentration in the lung, which we have demonstrated in our cases, is responsible for the tissue damage. The substances present in the eosinophilic granules which could be implicated are hydrolases, myloperoxidases, or the basic protein of the crystalloid internum, ${ }^{26}$ prostaglandins, ${ }^{27}$ and thromboplastin. ${ }^{28}$ The cause of degranulation is not clear; however it seems likely that again an immunological mechanism may be implicated. Eosinophils can be stimulated to degranulate in vitro by immune complexes, ${ }^{26}$ aggregated $\operatorname{IgG},{ }^{29}$ and foetal calf serum, ${ }^{30}$ and it is possible that a similar type of stimulus may have been acting in these cases. In one case we found IgG in the lung but we did not identify immune complexes. Eosinophils also produce a pyrogen ${ }^{31}$ and its release may be the explanation of the pyrexia seen in these cases. The dramatic response to steroids could be caused by their eosinopenic effect and by the stabilising effect on cell membranes which would prevent degranulation occurring.

The crystalline cytoplasmic inclusions within macrophages are probably the early intracellular stages of the formation of Charcot-Leyden crystals, ${ }^{32}$ which are often present in chronic eosinophilic pneumonia ${ }^{3}$ although they were not seen in histological sections in our cases. The pentalaminar inclusions, which have not previously been found in chronic eosinophilic pneumona, ${ }^{1920}$ resemble the intracytoplasmic inclusions seen in histocytosis $\mathrm{X},{ }^{33}$ Langerhans cells of the epidermis, ${ }^{34}$ and macrophages in the lungs in the usual type of interstitial pneumonia and bronchioalveolar carcinoma. ${ }^{35}$ These inclusions are probably formed from the surface membrane as the result of endocytosis. ${ }^{36}$

The histological features of the pneumonic process are not unique to this form of pulmonary eosinophilia. An eosinophilic pneumonia may be present in Löffler's syndrome, ${ }^{37}$ allergic bronchopulmonary aspergillosis, polyarteritis nodosa, and tropical eosinophilia. ${ }^{38}$ The diagnosis, therefore, depends upon clinical as well as histological features, and a search for aetiological factors is crucially important. This needs particular emphasis in asthmatic patients, since all the presenting features in table 3 (with the exception of the typical radiographic pattern, which is not always present) may occur in allergic bronchopulmonary aspergillosis or tropical eosinophilia. In this context, our finding of normal serum IgE levels in all our patients is interesting, since very high levels are typical of the latter two diseases. However, IgE levels have not been reported previously in chronic eosinophilic pneumonia, and their value as a discriminant requires confirmation.

Crofton et $a l^{1}$ emphasised that cases of pulmonary eosinophilia form a continuum, and that their classification was arbitrary. Our cases illustrate this. Criteria based on the duration of the illness or the presence of asthma may be transgressed both by cryptogenic cases like ours, and by cases where an agent such as a drug or parasite is incriminated. At present chronic eosinophilic pneumonia appears to be a genuine entity on clinical and histological grounds. This is useful therapeutically but exploration of its pathogenesis is overdue.

We are indebted to Dr RA Parkins and Dr P Snashall for permission to publish details of their cases. We would like to thank Mr RA Barnett and $\mathrm{Mr} \mathrm{TA}$ Bull for technical assistance.

\section{References}

1 Crofton JW, Livingstone JL, Oswald NC, Roberts ATM. Pulmonary eosinophilia. Thorax 1952; 7:1-35.

2 Carrington CB, Addington WW, Goff AM et al. Chronic eosinophilic pneumonia. $N$ Engl J Med 1969; 280:787-98.

3 Liebow AA, Carrington CB. The eosinophilic pneumonias. Medicine (Baltimore) 1969; 48: 251-85.

4 Cotes JE. Lung function. Third edition. Oxford: Blackwell Scientific Publications, 1975.

5 Black LF, Offord K, Hyatt RE. Variability in the maximum expiratory flow volume curve in asymptomatic smokers and in non-smokers. $\mathrm{Am}$ Rev Respir Dis 1974; 110:282-92.

6 Buist SA, Ross BB. Predicted values for closing volumes using a modified single breath nitrogen test. Am Rev Respir Dis 1973; 107:744-52.

7 Buist SA, Ross BB. Quantitative analysis of the alveolar plateau in the diagnosis of early airway obstruction. Am Rev Respir Dis 1973; 108: 1078-87. 
8 Broch OJ. A case of transient pulmonary infiltration with eosinophilia, with fatal issue after treatment by adrenalin spray for asthma. Acta Med Scand 1943; 113:311-8.

9 Christoforidis AJ, Molnar W. Eosinophilic pneumonia. JAMA 1960; 173:157-61.

10 Ford RM. Transient pulmonary eosinophilia and asthma. Am Rev Respir Dis 1966; 93:797-803.

11 Levin DC. The "PIE" syndrome; pulmonary infiltrates with eosinophilia: a report of three cases with lung biopsy. Radiology 1967; 89:461-5.

12 Perrault JL, Janis M, Wolinsky $\mathrm{H}$. Resolution of chronic eosinophilic pneumonia with corticoid therapy. Ann Intern Med 1971; 74:951-4.

13 Robertson CL, Shackelford GD, Armstrong JD. Chronic eosinophilic pneumonia. Radiology 1971; 101:57-61.

14 Scadding JG. Eosinophilic infiltrations of the lungs in asthmatics. Proc $R$ Soc Med 1971; 64: 381-92.

15 Case Records of the Massachusetts General Hospital. N Engl J Med 1972; 286:1205-10.

16 Citro LA, Gordon ME, Miller WT. Eosinophilic lung disease. $A J R$ 1973; 117:787-97.

17 Rao M, Steiner P, Rose JS, Kassner EG, Kottmeier P, Steiner M. Chronic eosinophilic pneumonia in a one-year-old child. Chest 1975; 68: 118-20.

18 Morrissey WL, Gaensler EA, Carrington CB, Turner HG. Chronic eosinophilic pneumonia. Respiration 1975; 32:453-68.

19 Rogers RM, Christiansen JR, Coalson JJ, Patterson CD. Eosinophilic pneumonia. Chest 1975; 68:665-71.

20 Kanner RE, Hammar SP. Chronic eosinophilic pneumonia. Chest 1977; 71:665-71.

21 Case Records of the Massachusetts General Hospital. $N$ Engl J Med 1977; 297:155-61.

22 Angelillo VA, Kanner RE, Renzetti AD Jnr. Chronic eosinophilic pneumonia. Am J Med Sci 1977; 273:279-87.

23 Gaensler EA, Carrington CB. Peripheral opacities in chronic eosinophilic pneumonia: the photographic negative of pulmonary edema. $A J R$ 1977; 128:1-13.

24 Ottesen EA. Eosinophilia and the lung. In: Kirkpatrick $\mathrm{CH}$, Reynolds HY (eds). Immunologic and infectious reactions in the lung. New
York: Marcel Dekker Inc, 1976: 289-332.

25 Spry CJF, Tai PC. Studies on blood eosinophilg II. Patients with Löffler's cardiomyopathy. Cli Exp Immunol 1976; 24:423-34.

26 Archer GT, Hirsch J. Motion picture studies oo degranulation of horse eosinophils during phago cytosis. J Exp Med 1963; 118:287-93.

27 Hubscher T. Role of eosinophil in the allergie reactions II. Release of prostaglandins fromhuman eosinophilic leucocytes. J Immunol 1975 114:1389-93.

28 Malkiewicz B, Pajdak W, Okulski J, Lisiewicz $\mathbf{P}_{\times}^{\overrightarrow{7}}$ Recherches sur l'activité thromboplastique desi éosinophiles d'un malade atteint de leucémie éosinophilique. Haematologia 1971; 5:439-46.

29 Zucker-Franklin D. Electron microscopic studies of human granulocytes: structural variations related to function. Semin Hematol 1968; 5:109卫 33.

30 Parmley RT, Spicer SS. Altered tissue eosinophils in Hodgkin's Disease. Exp Mol Pathol 1975; 23t 70-82.

31 Mickenberg ID, Root RK, Wolf SM. Bactericidate and metabolic properties of human eosinophilso Blood 1972; 39:67-80.

32 El-Hashimi W. Charcot-Leyden crystals. Am 5 Pathol 1971; 65:311-23.

33 Basset F, Escaig J, Le Crom M. A cytoplasmiø membranous complex in Histiocytosis X. Cance 1972; 29:1380-6.

34 Birbeck MS, Breathnach AS, Everall JD. A electron microscope study of basal melanocytes and high-level clear cells. J Invest Dermatol 1961 37:51-63.

35 Basset F, Soler P, Wyllie L, Mazin F, Turiaf J? Langerhans' cells and lung interstitium. $A n n N$ Y Acad Sci 1976; 278:599-611.

36 Hashimoto $\mathrm{K}$. Lanthanum staining of Langer hans' cells. Communication of Langerhans' cel\$ granules with extracellular space. Arch Dermato 1970; 102:280-90.

37 Bedrossian CWM, Greenberg SD, Williams LJ Jr Ultrastructure of the lung in Leoffler's pneu monia. Am J Med 1975; 58:438-43.

38 Katzenstein A-L, Liebow AA, Friedman PJ Bronchocentric granulomatosis mucoid impaction and hypersensitivity reactions to fungi. $A m R e$ 仡 Respir Dis 1975; 111:497-537. 